and its complications in Vietnam: A national health insurance database study. Diabetes Res Clin Pract. 2020;162:108051.

doi:10.1016/j.diabres.2020.108051

2. Stratton IM. Association of glycaemia with macrovascular and microvascular complications of type 2 diabetes (UKPDS 35): prospective observational study. BMJ. 2000;321(7258):405412. doi:10.1136/bmj.321.7258.405

3. Meneghini L, Kesavadev J, Demissie M, Nazeri A, Hollander P. Once-daily initiation of basal insulin as add-on to metformin: a 26-week, randomized, treat-to-target trial comparing insulin detemir with insulin glargine in patients with type 2 diabetes. Diabetes Obes Metab. 2013;15(8):729736. doi: $10.1111 /$ dom. 12083

4. Nguyen KT, Diep BTT, Nguyen VDK, Van Lam H, Tran KQ, Tran NQ. A cross-sectional study to evaluate diabetes management, control and complications in 1631 patients with type 2 diabetes mellitus in Vietnam (DiabCare Asia). Int J Diabetes Dev Ctries. 2020;40(1):70-79. doi:10.1007/ s13410-019-00755-W
5. Kieu TTM, Trinh HN, Pham HTK, Nguyen TB, Ng JYS. Direct non-medical and indirect costs of diabetes and its associated complications in Vietnam: an estimation using national health insurance claims from a cross-sectional survey. BMJ Open. 2020;10(3):e032303. doi:10.1136/ bmjopen-2019-032303

6. Beaudet A, Clegg J, Thuresson P-O, Lloyd A, McEwan P. Review of Utility Values for Economic Modeling in Type 2 Diabetes. Value Health. 2014; 17(4):462-470. doi:10.1016/j.jval.2014.03.003

7. Permsuwan $U$, Thavorn $K$, Dilokthornsakul $\mathbf{P}$, Saokaew S, Chaiyakunapruk N. Costeffectiveness of insulin detemir versus insulin glargine for Thai type 2 diabetes from a payer's perspective. J Med Econ. 2017;20(9):991-999. doi:10.1080/13696998.2017.1347792

8. Guillermin A-L, Samyshkin $Y$, Wright $D$, Nguyen T, Villeneuve J. Modeling the lifetime costs of insulin glargine and insulin detemir in type 1 and type 2 diabetes patients in Canada: a metaanalysis and a cost-minimization analysis. J Med Econ. 2011;14(2):207-216. doi:10.3111/ 13696998.2011 .561390

\title{
GIÁ TRI CHỌC HÚT BẰNG KIM NHỎ U TUYẾN MANG TAI TẠI BỆNH VIÊ̂N ĐẠI HỌC Y DƯợC TP.HCM TỪ 2020 ĐẾN 2021
}

\section{TÓM TẮT}

Đă̆t vấn đê: Chọc hút bằng kim nhỏ (FNA) trước phẫu thuât là cân lâm sàng cân thiết trong việc chẩn đoán và điều trị u tuyến mang tai. Mục tiêu nghiên cứu: Đánh giá giá trị chọc hút bằng kim nhỏ (FNA) trong chẩn đoán u tuyến mang tại Bệnh viện Đại học Y Dược TP.HCM. Phương pháp nghiên cứu: Mô tả dọc hồi cứu 60 hồ sơ bênh án được chẩn đoán u tuyến mang tai tại Bệnh viện Đại học Y Dược TP.HCM trong 2 năm 2020 - 2021. Kết quả nghiên cứu: Chọc hút tế bào bằng kim nhỏ (FNA): 21,7\% không xác đinh đước chẩn đoán. Kết quả chẩn đoán u ác tính FNA chiểm $8,3 \%$. Kết quả giải phẫu bệnh: u lành tính trong 96,6\%; u ác tính trong 3,4\%. Giá trị của siêu âm trong chẩn đoán u tuyến mang tai: Độ nhạy $100 \%$; Đô đắc hiêu 94,8\%; Giá trị chân đoán dương 40\%; Giá trị chẩn đoán âm 100\%; Độ chính xác 95\%. Giá trị của FNA trong chẩn đoán u tuyến mang tai: Độ nhạy 100\%; Độ đặc hiệu 93,3\%; Giá trị chẩn đoán dương 40\%; Giá trị chẩn đoán âm 100\%; Đô chính xác 93,6\%. Kết Luận: Chọc hút tế bào bằng kim nhỏ (FNA) có giá trị cao trong chẩn đoán u lành tính tuyến mang tai. Tuy nhiên, kỹ thuâtt lấy mẫu không tốt dẫn đến không xác định được chẩn đoán.

*Đai Hoc Y Dước TP.Hồ Chí Minh

Chịu trách nhiệm chính: Bùi Kim Ngân

Email: bskimngan93@gmail.com

Ngày nhân bài: 6.5.2021

Ngày phản biên khoa hoc: 24.6.2021

Ngày duyệt bài: 6.7.2021

\section{Bùi Kim Ngân*, Võ Hiếu Bình*}

Tư khóa: Chọc hút bằng kim nhỏ (FNA), u tuyến mang tai, siêu âm tuyến mang tai.

\section{SUMMARY}

DIAGNOSTICVALUE OF FINE-NEEDLE ASPIRATION CYTOLOGY IN THE PAROTID GLAND TUMORS IN UNIVERSITY MEDICAL CENTRE IN HO CHI MINH CITY FROM 2020 TO 2021

Background: Fine needle aspiration (FNA) before surgery is needed in clinical diagnosis and treatment of parotid gland tumors. Objective: This study aimed to determine the diagnostic value of fine needle aspiration biopsy (FNA) and of its contribution to the management of parotid gland tumors. Methods: We conducted a retrospective study of 60 patients who had undergone parotidectomy as well as preoperative fine needle aspiration biopsy. Results: Results of the fine-needle aspiration cytology: $21,7 \%$ of the cases were evaluated as non-diagnostic. FNA melanoma diagnosis results accounted for $8.3 \%$. The histopathological examination: benign tumors in $96.6 \%$; cancer in $3.4 \%$. The value of utrasound in the parotid gland tumors: The sensitivity 100\%; The specificity 94,8\%; Diagnostic accuracy was 95\%, Positive predictive value was $40 \%$ and negative predictive value $100 \%$. Diagnostic value of FNA in the parotid gland tumors: The sensitivity $100 \%$; The specificity 93,3\%; Diagnostic accuracy was 93,6\%, Positive predictive value $40 \%$ and negative predictive value $93,6 \%$. Conclusion: FNAC generally provided the correct histological diagnosis for benign tumors. 
However, poor sampling techniques lead to an unidentified diagnosis.

Keywords: Fine-needle aspiration, parotid gland tumors, utrasound of parotid gland.

\section{I. ĐẶT VẤN ĐỀ}

Các khối u tuyến nước bọt là nhóm bệnh tương đối hiếm gặp. Khoảng 1,5 - 2 trường hợp khối u tuyến nước bọt trên 100.000 dân được chẩn đoán tại $M \tilde{y}^{(1)}$. Trong đó, u tuyến mang tai chiếm khoảng $80 \%$ trong nhóm các khối u tuyến nước bọt. Trong số các u tuyến mang tai, 70 $80 \%$ là lành tính, trong những khối u biểu mô lành tính khoảng $80 \%$ nằm ở thùy nông ${ }^{(1)}$ và phổ biến nhất là u tuyến đa dạng (Pleomorphic adenoma) chiếm khoảng $80 \%$, những tỷ lệ này còn được các y văn hay gọi là "quy luât $80^{0 "}$ (2). Ngoài ra, khối trong tuyến mang tai cũng có thể là hạch lành tính, vì có một số lượng đáng kể hạch bạch huyết hiện diện trong tuyến mang tai

$\mathrm{U}$ tuyến nước bọt mang tai ở trẻ em không phổ biến nhưng tần suất u ác tính ở trẻ em cao hơn người lớn (3). Tất cả các khối u ở trẻ em đều cần được đánh giá chẩn đoán kỹ lưỡng. Loại u lành tính nhất thường gặp ở trẻ em là u mạch máu.

Khảo sát đặc điểm của u tuyến mang tai qua chơc hút bằng kim nhỏ (FNA) trước mổ và giải phẫu bệnh sau mổ là chìa khóa quan trọng trong quá trình điều trị như có thể góp phần tránh được phẫu thuật không đáng có. Với mục đích làm rõ giá trị của FNA trong chẩn đoán u tuyến mang tai, góp phần lựa chọn cách điều trị phẫu thuâat tốt nhất, phù hợp nhất cho bệnh nhân, ít để lại biến chứng, chúng tôi tiến hành: "Giá trị chọc hút bằng kim nhỏ u tuyến mang tai tại Bệnh viện đại hoc Y dược TP.HCM từ 2020 đến 2021".

Mục tiêu nghiên cứu. Xác định kết quả chọc hút bằng kim nhỏ (FNA) u tuyến mang tai đối chiếu với giải phẫu bệnh sau mổ tại bệnh viên Đại hoc Y Dước TP.HCM cơ sở 1 và cơ sở 2 từ 2020 tới 2021

\section{II. ĐỐI TƯợNG VÀ PHƯƠNG PHÁP NGHIÊN CỨU}

2.1. Đối tượng nghiên cứu. Các bệnh nhân phẫu thuật $u$ tuyến mang tai tại khoa Tai mũi họng Bệnh viện Đại học Y Dược TP.HCM cơ sở 1 và cơ sở 2 từ 2020 tới 2021 phù hợp với tiêu chuẩn chọn bệnh.

\subsubsection{Tiêu chuẩn chọn bệnh}

- Bệnh nhân là người Việt Nam đến khám tại phòng khám Tai mũi họng Bệnh viện Đại học Y Dược TP.HCM cơ sở 1 và cở sở 2 từ 2020 tới 2021, được chẩn đoán u tuyến mang tai qua lâm sàng và chẩn đoán hình ảnh.

- Đồng ý hợp tác làm thủ thuật sinh thiết qua kim nhỏ (FNA) trước mổ dưới sự hướng dẫn của siêu âm.

- Điều trị bằng phương pháp phẫu thuật và có thực hiện giải phẫu bệnh sau mổ.

2.1.2. Tiêu chuẩn loại trừ bệnh nhân

- Bệnh nhân không đủ tỉnh táo và sức khỏe để cung cấp thông tin khi tham gia nghiên cứu.

- Bệnh nhân không đồng ý tham gia nghiên cứu.

- Hồ sơ bệnh án thiếu thông tin theo thiết kế bộ câu hỏi

\subsection{Phương pháp nghiên cứu}

2.2.1. Thiết kế nghiên cứu: Nghiên cứu hồi cứu. Thời gian tiến hành từ 2020 đến 2021 tại khoa Tai Mũi Họng bệnh viện đại học Y Dược TP.HCM cơ sở 1 và cơ sở 2.

\subsubsection{Cõ̃ mẫu:}

Cõ mẫu: $N=Z^{2}{ }_{1-a / 2} P(1-P) / d^{2}=85$

- Z: trị số của phân phối chuẩn $(Z=1,96)$

- a: xác xuất sai lầm loại $\mathrm{I}(\mathrm{a}=0,05)$

- $d$ : sai số cho phép $(d=0.1)$

- p: tỉ lệ chẩn đoán phù hợp giữa FNA và giải phẫu bệnh $(P=0,667)$ : theo nghiên cứu của tác giả Huỳnh Thị Mỹ Hiền năm 2014 tỉ lệ chẩn đoán phù hợp giữa FNA và giải phẫu bệnh là $66,7 \%$.

Cỡ mẫu thu thập $n=60$

2.2.3. Phương pháp chọn mẫu: Chọn mẫu toàn bộ.

2.2.4. Thời gian nghiên cứu. Chúng tôi lấy mẫu từ tháng 01/2020 đến tháng 06/2021.

\subsection{Tiến hành nghiên cứu}

Bước 1: Chọn lựa bệnh nhân phù hợp với tiêu chuẩn chọn mẫu

Bước 2: Tiến hành ghi nhận thông tin một số đặc điểm lâm sàng; qua hỏi bệnh và thăm khám lâm sàng.

Bước 3: Tiến hành ghi nhân thông tin qua kết quả cận lâm sàng:

Siều âm đánh giá đặc điểm u tuyến mang tai:

- Vị trí: thùy nông, thùy sâu hoặc cả 2.

- Kích thước khối u xếp theo phân nhóm của Ủy ban Ung thư Hoa Kỳ (AJCC): đo kích thước đường kính lớn nhất tìm được và xếp vào nhóm các kích thước tương ứng.

- Ranh giới u: rõ, không rõ

- Mật độ u: tăng âm, giảm âm, đồng âm, hỗn hợp.

- Cẩu trúc u: đồng nhất, không đồng nhất.

Bước 4: Ghi nhận thông tin mô bệnh học qua FNA trước mổ: thống kê kết quả

- Có lấy được tiêu bản không?

- Kết quả tế bào học: lành tính hoặc ác tính hoặc không xác định.

- Kết quả tế bào cụ thể từng loại u: u tuyến đa dạng, u Warthin, nang, viêm, ung thư biểu mô nhày bì, .... 
Bước 5: Ghi nhận thông tin giải phẫu bệnh sau mổ: thống kê kết quả

- Kết quả mô học: lành tính hoặc ác tính.

- Kết quả mô học cụ thể từng lioại u: u tuyến đa dạng, u Warthin, nang, viêm, ung thư biểu mô nhày bì, ....

Bước 6: Nhập, làm sạch, phân tích số liệu.

\subsection{Biến số}

Siêu âm: vị trí thùy của u, kích thước u, ranh giới, cấu trúc, mật độ, bản chất khối u.

Chọc hút bằng kim nhỏ dưới hướng dẫn của siêu âm lấy tế bào khối $u$, nhuộm phiến đồ tế bào theo PAP sau đó đọc kết quả:

\section{Lành tính:}

- U tuyến đa hình.

- U Warthin.

- Nang tuyến nước bọt.

- Các u lành tính khác

Ác tính:

- UTBM tuyến nang

- UTBM nhày bì

- UTBM ống tuyến

- Các u ác tính khác

Không xác định

Đọc kết quả trên tiêu bản mô bệnh học của khối u được nhuộm HE sau khi phẫu thuật:

Lành tính:

- U tuyến đa hình.

- U Warthin.

- U tế bào cơ biểu mô lành tính.

- U lành tính khác.

Ác tính:

- UTBM nhày bì.

- UTBM tuyến nang.

- UTBM ông tuyến

- Các u ác tính khac.

\subsection{Phân tích và xử lý số liêu}

- Nhâp và phân tích số liệu bắng phần mềm SPSS 22.0

- Các biến định tính được mô tả bằng tân số và tỉ lệ phần trăm. Các biển định lượng có phân phối chuẩn được mô tả bằng trung bình và độ lệch chuẩn. Các biến định lượng có phân phối không chuẩn được mô tả bằng trung vị. Khoảng tin cậy $95 \%$ và giá trị $p$ của các ti lệ này cũng được báo cáo.

- So sánh các biến định lượng bằng T-test, so sánh các biến định tính bằng kiểm định $x^{2}$, có ý nghĩa thống kê khi $p<0,05$.

2.6. Khía canh đao đức của đề tài: Nghiên cứu này được sự chấp thuận của Hội đồng đạo đức trong nghiên cứu y sinh hoc Đai hoc $Y$ Dược TP. Hồ Chí Minh căn cứ theo quyết định số 505/HĐĐĐ-ĐHYD ngày 25/08/2020.
III. KẾT QUẢ NGHIÊN CỨU

\section{Kết quả xét nghiệm FNA}

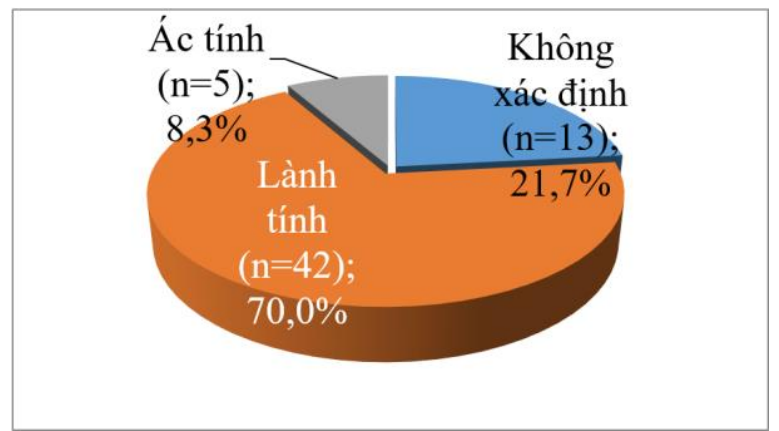

Biều đồ 1.1: Chẩn đoán u tuyến mang tai trên xét nghiêm FNA

Nhân xét: Trong các khối u xác đinh được chẩn đoán kết quả u lành tính trong 42 trường hợp, chiếm 70\%. Có 5 trường hợp u ác tính, chiếm $8,3 \%$.

Bảng 1.1: Đặc điểm hình thái trên FNA

\begin{tabular}{|c|c|c|}
\hline Đặc điểm & $\begin{array}{c}\text { Tần số } \\
(\mathbf{n = 6 0 )}\end{array}$ & $\begin{array}{c}\text { Tỷ lề } \\
\mathbf{( \% )}\end{array}$ \\
\hline Không rõ chấn đoán & $\mathbf{1 3}$ & $\mathbf{2 1 , 7}$ \\
\hline Lành tính & & \\
\hline U tuyến đa dạng & 21 & 35,0 \\
\hline U Warthin & 13 & 21,6 \\
\hline Nang & 5 & 8,3 \\
\hline Tố chức viêm & 3 & 5,0 \\
\hline Acc tính & & \\
\hline Carcinom ống tuyến & 2 & 3,3 \\
\hline Carcinom nhày bì & 2 & 3,3 \\
\hline Nghi ngỡ ác tính & 1 & 1,7 \\
\hline
\end{tabular}

Nhận xét: U tuyến đa dạng là khối u thường gặp nhất thuộc nhóm u lành tính chiếm 35\% trong tổng loại $u$, loai thường gặp thứ 2 là u Warthin chiếm $21,6 \%$. Nang và tổ chức viêm chiếm lần lượt là $8,3 \%$ và $5 \%$. Trong nhóm u ác tính, carcinom ống tuyến và carcinom nhày bì đều chiếm 3,3\%; chẩn đoán nghi ngờ ác tính chiếm 1,7\%.

2. Kết quả xét nghiệm giải phẫu bệnh

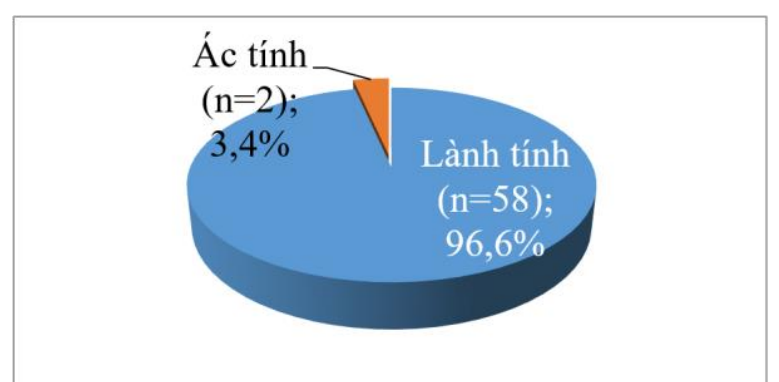

Biểu đồ 2.1: Chẩn đoán u tuyến mang tai trên GPB

Nhận xét: Kết quả GPB sau mổ xác định được ÜBMLT trong 96,6\%; UBMAT trong 3,4\%. 


Bảng 2.2: Kêt quả xét nghiệm giải phẫu bệnh
\begin{tabular}{|c|c|c|}
\hline Đặc điểm & $\begin{array}{c}\text { Tân số } \\
(\mathbf{n = 6 0 )}\end{array}$ & $\begin{array}{c}\text { Tỷ lề } \\
\mathbf{( \% )}\end{array}$ \\
\hline Lành tính & & \\
\hline U tuyến đa dạng & 24 & 40,0 \\
\hline U Warthin & 22 & 36,4 \\
\hline U tuyến tế bào đáy & 1 & 1,7 \\
\hline Tố chức viêm & 3 & 5,0 \\
\hline Nang & 4 & 6,7 \\
\hline U tế bào Swanoma & 1 & 1,7 \\
\hline U nhú gai & 1 & 1,7 \\
\hline $\begin{array}{c}\text { U Phồng bào + U tuyến } \\
\text { lympho bào của tuyến }\end{array}$ & 1 & 1,7 \\
\hline
\end{tabular}

\begin{tabular}{|c|c|c|}
\hline U mạch máu & 1 & 1,7 \\
\hline Ác tính & & \\
\hline Carcinom ống tuyến & 1 & 1,7 \\
\hline Carcinom nhày bì & 1 & 1,7 \\
\hline
\end{tabular}

Nhận xét: Trong các u lành tính, u tuyến đa dang chiếm đa số chiếm $40 \%$ trong tổng $\mathrm{u}$, u Warthin chiếm 36,4\%; nang chiếm 6,7\%; tổ chức viêm chiếm $5 \%$; còn lại các loại u tế bào Swanoma, u nhú gai, u phồng bào kết hợp với u tuyến lympho bào của tuyến và u mạch máu đều chiếm $1,7 \%$. Trong nhóm u ác tính, carcinom ống tuyến và carcinom nhày bì đều chiếm $1,7 \%$.

\section{Giá trị chẩn đoán}

Bảng 3.1: Giá trị chẩn đoán của FNA trong chẩn đoán u tuyến mang thai

\begin{tabular}{|c|c|c|c|c|c|c|c|c|}
\hline \multirow{2}{*}{ CLS } & \multicolumn{2}{|c|}{ Giải phâuu bệnh } & Se & Sp & $\begin{array}{c}\text { Vp } \\
(+)\end{array}$ & $\begin{array}{c}\text { Vp } \\
\mathbf{( - )}\end{array}$ & $\begin{array}{c}\text { Độ chính } \\
\text { xác }\end{array}$ & p \\
\hline Ung thư & Lành tính & & & & & & \\
\hline Siêu âm & & & & & & & & \\
\hline Lành $(\mathrm{n}=5)$ & $2(40,0)$ & $3(60,0)$ & 1,0 & 0,948 & 0,40 & 1,0 & 0,95 & 0,000 \\
\hline FNA $(\mathrm{n}=55)$ & 0 & $55(100)$ & & & & & & \\
\hline Ac tính $(\mathrm{n}=5)$ & $2(40,0)$ & $3(60,0)$ & 1,0 & 0,933 & 0,40 & 1,0 & 0,936 & 0,000 \\
\hline Lành tính $(\mathrm{n}=42)$ & 0 & $42(100)$ & & & & & & \\
\hline
\end{tabular}

Nhận xét: Giá trị của siêu âm trong chẩn đoán u tuyến mang tai: Độ nhạy $100 \%$; Độ đặc hiệu 94,8\%; Giá trị chẩn đoán dương 40,0\%; Giá trị chẩn đoán âm 100\%; Độ chính xác 95\%.

Giá trị của FNA trong chẩn đoán u tuyến mang tai: Độ nhạy 100\%; Độ đặc hiệu 93,3\%; Giá trị chẩn đoán dương $40,0 \%$; Giá trị chẩn đoán âm 100\%; Độ chính xác 93,6\%.

\section{BÀN LUÂ̂N}

Nghiên cứu của chúng tôi xét FNA có giá trị trong chẩn đoán u tuyến mang tai: Độ nhạy của phương pháp là 100\%; độ đặc hiệu 93,3\%; giá trị chẩn đoán dương là $40 \%$; giá trị chẩn đoán âm là $100 \%$ và đô chính xác là $93,6 \%$. Phù hợp với nghiên cứu của Đinh Xuân Thành ${ }^{(4)}$ năm 2010 tuy nhiên giá trị chẩn đoán dương trong nghiên cứu của chúng tôi thấp hơn, tác giả Đinh Xuân Thành với mục đích chẩn đoán phân biệt

tổn thương lành tính với ác tính với độ nhạy của FNA là $100 \%$, độ đặc hiệu là $93 \%$, giá trị tiên đoán dương là $100 \%$ và giá trị tiên đoán âm là $100 \%$. So sánh với nghiên cứu của Chauhan $\mathrm{N}^{(5)}$ năm 2019: FNA có độ nhạy là $81,81 \%$; độ đặc hiệu là $94,73 \%$, giá trị tiên đoán dương tính là $90 \%$ và giá trị dự đoán âm tính là $90 \%$, độ chính xác là $90 \%$. So sánh với ghiên cứu Dhanani $R^{(6)}$ của năm 2020: độ nhạy, độ đặc hiệu, giá trị chẩn đoán dương tính và âm tính, độ chính xác của FNA lần lượt là $88,9 \%$; 97,9\%; 93\%; $96,7 \% ; 95,8 \%$. So sánh với nghiên cứu của Stavros $\operatorname{Archondakis}^{(7)}$ năm 2021 cho thây là độ chính xác chẩn đoán FNA để phân biêt bênh lành tính và ác tính là 93,3\%; độ đặc hiệu là $97,5 \%$ và độ nhạy là $82,2 \%$. Giá trị dự đoán dương tính và âm tính lần lượt là $93,2 \%$ và $87,2 \%$.

Bảng 3.2: Bảng so sánh giá trị của FNA

\begin{tabular}{|c|c|c|c|c|c|c|}
\hline Tác giả & Cỡ mẫu & Độ nhạy & $\begin{array}{c}\text { Độ đặc } \\
\text { hiệu }\end{array}$ & $\begin{array}{c}\text { Giá trị chấn } \\
\text { đoán }(+)\end{array}$ & $\begin{array}{c}\text { Giá trị chấn } \\
\text { đoán } \mathbf{( - )}\end{array}$ & $\begin{array}{c}\text { Độ chính } \\
\text { xác }\end{array}$ \\
\hline Đinh Xuân Thành 2010(4) & 34 & $97 \%$ & $100 \%$ & $100 \%$ & $100 \%$ & \\
\hline Chauhan N 2019(5) & 31 & $81,8 \%$ & $94,7 \%$ & $90,0 \%$ & $90,0 \%$ & $90 \%$ \\
\hline Dhanani R 2020(8) & 193 & $88,9 \%$ & $97,9 \%$ & $93 \%$ & $96,7 \%$ & $95,8 \%$ \\
\hline Archondakis S 2021(7) & 102 & $82,2 \%$ & $97,5 \%$ & $93,2 \%$ & $87,2 \%$ & $93,3 \%$ \\
\hline Chúng tôi 2021 & 60 & $100 \%$ & $93,3 \%$ & $40,0 \%$ & $100 \%$ & $93,6 \%$ \\
\hline
\end{tabular}

Trong thực tế, u tuyến mang tai thường có triệu chứng nghèo nàn, ít gây khó chịu, bênh nhân đến khám và điều trị muộn, khối u đã lớn, ảnh hưởng nhiều đến chức năng vùng mặt như liệt mặt, khít hàm và thẫm mỹ của bệnh nhân. Việc phát hiện khối u tuyến mang tai khá dễ dàng trên lâm sàng với sự hỗ trợ của các cận lâm sàng chẩn đoán hình ảnh như siêu âm ở tất 
cả các bênh nhân và môt số bênh nhân được chụp CLVT. Do nhiều yểu tố kể trên nên đối tượng nghiên cứu của chúng tôi là nhóm đối tượng đã được sàng lọc trước khi thực hiện FNA, hầu hết các khối sưng vùng mang tai đã gợi ý có khối u trong tuyến mang tai. Dưới sự hướng dẫn của siêu âm cũng là cận lâm sàng có độ nhạy, độ đặc hiệu, độ chính xác cao khiến cho kết quả FNA của nghiên cứu chúng tôi đạt được cao hơn rõ rệt với một số tác giả ngoài nước.

Về độ nhạy, theo kết quả nghiên cứu của chúng tôi FNA có độ nhạy ở mức cao 100\%; cứ 100 người bị u tuyến mang tai thì FNA phát hiện được khối u ở 100 người. Kết quả cao hơn so với các nghiên cứu của trong và ngoài nước của các tác giả Chauhan $\mathrm{N}^{(5)} 81,8 \%$; Dhanani $\mathrm{R}^{(8)} 88,9 \%$ và Archondakis $S^{(7)} 82,2 \%$ và tác giả Đinh Xuân Thành ${ }^{(4)}$ là $97 \%$. Cỡ mẫu của nghiên cứu chúng tôi và các nghiên cứu khác không tương đồng nhau, sự khác nhau về tỷ lệ này có thể ảnh hưởng bởi nhiều yếu tố: kỹ thuật lấy mẫu u tuyến mang tai, kinh nghiệm đọc kết quả FNA. Qua kết quả trên cho thấy quan điểm xem giá trị chẩn đoán của FNA là chìa khóa chẩn đoán ban đầu của u tuyến mang tai là có căn cứ, hướng cho các bác sỹ lâm sàng xem FNA như một cận lâm sàng thường quy cần thiết để hố trợ chẩn đoán được chính xác hơn.

Về đổ đă̆c hiêu, theo kết quả nghiên cứu của chúng tôi FNA có độ đặc hiệu cao 93,3\%; cứ 100 người không bị u tuyến mang tai thì FNA xác định đúng được $\approx 94$ người là không có khối u thật sự.

Về giá trị tiên đoán dương, theo kết quả nghiên cứu của chúng tôi FNA có giá trị tiên đoán dương thấp $40 \%$; cứ 100 người có FNA nghi ngờ ung thư tuyến mang tai thì có $\approx 40$ người có ung thư thật sự. Kết quả thấp hơn so với các nghiên cứu trong nước và ngoài nước, theo tác giả Chauhan $\mathrm{N}^{(5)}$ là $90 \%$; Dhanani $\mathrm{R}^{(8)}$ $93 \%$ và Archondakis $S^{(7)} 93,2 \%$ và Đinh Xuân Thành ${ }^{(4)}$ là $99 \%$. Sự khác biệt lớn này có thể do ảnh hưởng bởi cớ mẫu, đặc điểm của mẫu nghiên cứu, kỹ thuật lấy FNA và kinh nghiệm của bác sĩ. Cỡ mẫu của chúng tôi nhỏ, đối tượng nghiên cứu ung thư tuyến mang tai chưa đa dang, số lượng ít, mẫu của chúng tôi đa phần là các khối u lành tính. Một số khối ung thư có kích thước nhỏ khó xác định, lấy không đúng tế bào u hoặc lượng tế bào đã lấy không đủ để biểu hiện đặc trưng của $u$. $U$ tuyến mang tai nói chung là dạng khối u đặc trưng bởi tính đa hình giữa từng loại $u$, có khi đa dạng kiểu hình trong cùng 1 khối u và mỗi loại u có một cấu trúc sắp xếp tế bào khác nhau những điều đó cũng là yếu tố ảnh hưởng đến nhận định của các bác sĩ chuyên khoa.

Về giá trị tiên đoán âm, theo kết quả nghiên cứu của chúng tôi FNA có giá trị tiên đoán âm cao 100\%; cứ 100 người có FNA nghi ngờ không ung thư thì có 100 người không ung thư thật sự. Kết quả này cao hơn so với cả các nghiên cứu trong và ngoài nước, khả năng nhận định u biểu mô lành tính trong nghiên cứu cao.

Nhìn chung, nghiên cứu của chúng tôi thực hiện FNA dưới sự hướng dẫn của siêu âm đã hạn chế được rất nhiều biến chứng khi chọc kim và tăng giá trị chính xác của FNA. Để chẩn đoán tế bào $\mathrm{u}$ qua chọc hút bằng kim nhỏ được thực hiện qua khá nhiều giai đoañ: siêu âm xác định vị trí, dùng kim nhỏ lấy mẫu, cố định mẫu trên lam, vận chuyển, lưu trữ tế bào và nhuộm Papanicolaou; mỗi giai đoạn này đều phải tuân thủ nghiêm ngăt quy trình vì chỉ cần có sai sót nhỏ ở 1 khâu nào đó cũng sẽ ảnh hưởng lớn đến kết quả đọc tế bào. Chọc hút bằng kim nhỏ (FNA) trong u tuyến mang tai là một cận lâm sàng chủ yếu lây tế bào của u với lượng rất ít, nên không thể tránh khỏi kết quả không trùng khớp với giải phẫu bệnh, mà giải phẫu bệnh được xem như tiêu chuẩn vàng trong chẩn đoán xác định bản chất $u$ tuyến mang tai. Trong nghiên cứu này, kết quả FNA cho thấy cận lâm sàng này có giá trị để gợi ý cho bác sĩ về chẩn đoán ban đầu trong u tuyến mang tai để đưa ra kế hoạch phẫu thuật hoặc bảo tồn, măcc dù tỷ lệ chẩn đoán dương kém nhưng do nghiển cứu của chúng tôi số khảo sát ung thư tuyến mang tai thấp nên cũng hạn chế trong việc đưa ra chẩn đoán về ung thư tuyến mang tai.

FNA là một kỹ thuật ít xầm lấn, hiếm có biến chứng và ít tốn kém hơn những cận lâm sàng khác. Hiện nay, kỹ thuật FNA khồng đòi hỏi nhiều dụng cụ, tiết kiệm thời gian có thể thực hiện ngày tai phòng khám mà không cần đển phòng mổ như kỹ thuật sinh thiết u; thao tác và kinh nghiệm chẩn đoán của các bác sĩ ngày càng chính xác khiến cho FNA có độ tin cậy ngày càng cao. Thông qua các kết quả trên cho thây FNA được xem là phương tiện chẩn đoán u tuyến mang tai tốt hiện nay tại Việt Nam.

\section{KẾT LUÂN}

Chọc hút tế bào bằng kim nhỏ (FNA) có giá trị cao trong chẩn đoán u lành tính tuyến mang tai. Tuy nhiên, việc đánh giá và phân loại các u lành tính còn rất kém. Chọc hút bằng kim nhỏ cho thấy độ nhạy, độ đặc hiệu và độ chính xác 
tốt. Độ nhạy: 100\%; độ đặc hiệu: 94,8\% ; độ chính xác: $93,6 \%$. Nên áp dụng thường quy kỹ thuật chọc hút bằng kim nhỏ (FNA) dưới hướng dẫn của siêu âm trong chẩn đoán u tuyến mang tai. Vì kỹ thuật này giá thành khá rẻ, ít xâm lấn, ít gây biến chứng, có thể linh hoạt làm tại phòng khám và có giá trị cao để chẩn đoán tế bào học của khối u, thông qua đó có thể lâp ra kế hoach điều trị, bảo tồn được dây thần kinh VII và tiên lượng được các biến chứng. Giải phẫu bệnh lý u tuyến mang tai vẫn là tiêu chuẩn vàng trong chẩn đoán xác định bản chất u tuyến mang tai.

\section{TÀl LIẸU THAM KHẢO}

1. Eric R. Carlson Robert A. Ord (2016), "Tumors of the Parotid Gland"Salivary Gland Pathology: Diagnosis and Management, 2nd Edition, Jonh Wiley \& Sons, Inc, Canada, pp. 233-259.

2. Almeslet A. S (2020), "Pleomorphic Adenoma: A Systematic Review", Int J Clin Pediatr Dent. 13(3), pp. 284-287.

3. Ord R A Carlson E R (2016), "Pediatric Salivary Gland Malignancies", Oral Maxillofac Surg Clin North Am. 28(1), pp. 83-9.

4. Đinh Xuân Thành; (2010), Nghiên cứu chẩn đoán và điều trị u tuyên nước bot mang tai, Luận án Tiến sỹ, Trường Đại học Y Hà Nội.

5. Chauhan N Shah j A (2019), "Parotid Gland Tumours: Our Experience", Indian J Otolaryngol Head Neck Surg. 71(3), pp. 378-382.

6. Dhanani R Iftikhar H (2020), "Role of Fine Needle Aspiration Cytology in the Diagnosis of Parotid Gland Tumors: Analysis of 193 Cases". 24(4), e508-e512.

7. Archondakis S, Roma M Kaladelfou E (2021), "Two-Year Experience of the Implementation of the Milan for Reporting Salivary Gland Cytopathology at a Private Medical Laboratory", Head Neck Pathol.

8. Dhanani R (2020), "Role of Fine Needle Aspiration Cytology in the Diagnosis of Parotid Gland Tumors: Analysis of 193 Cases". 24(4), e508-e512.

\section{HIÊ̂U QUẢ TẠO NGÀ SỬA CHỮA CỦA XI MĂNG CALCIUM SILICATE (BIODENTINETM) TRONG ỨNG DỤNG CHE TUỶ GIÁN TIẾP}

Trần Xuân Vĩnh*

\section{TÓM TẮT}

Mục tiêu: Đánh giá hiệu tạo ngà sửa chữa của xi măng calcium silicate (Biodentine ${ }^{\mathrm{TM}}$ ) trong ứng dụng lâm sàng che tuỷ gián tiếp. Đối tượng và phương pháp nghiên cứu: Bệnh nhân nữ 20 tuổi đau khi nhai hoặc uống nước nóng/lạnh vùng răng số 37. Khám lâm sàng ghi nhận răng 37 có tổn thương sâu răng lớn; răng đáp ứng với thử điện/lạnh. Dựa trên khám lâm sàng và hình ảnh $X$ quang, răng được chẩn đoán là viêm tủy có hồi phục. Răng được gây tê trước đă̆t đê cao su để cô lập răng. Mô ngà sẩu được loại bỏ bằng kỹ thuật loại bó ngà sâu chọn lọc một bước với mũi khoan tròn vô trùng và tay khoan cao tốc dưới nguồn nước. Xoang trám được khử trùng bằng gạc vô trùng thấm $\mathrm{NaOCl} 2,5 \%$ trước khi trám với Biodentine $^{T M}$ (Septodont, Saint Maur des Fosses Cedex, Pháp). Sau 1 tháng răng được trám kết thúc với resin composite (3M ESPE, St Paul, MN, USA). Đánh giá lâm sàng và $X$ quang được thực hiện sau 6 tháng và 1 năm. Kêt quả: Bệnh nhân có cơn đau nhe ngay sau khi điều trị, nhưng hết nhanh chóng. Sau 1 tháng, 6 tháng và 1 năm, bệnh nhân không có các triệu chứng bất thường, ăn nhai tốt. Răng đáp ứng với thử nghiệm điện và lạnh. Hình ảnh $X$ quang quanh chóp cho thấy có sự hình thành ngà sửa chữa ngay

*Đại Học Y Dược Tp. Hồ Chí Minh

Chịu trách nhiệm chính: Trân Xuân Vĩnh

Email: vinhdentist@yahoo.com

Ngày nhận bài: 7.5.2021

Ngày phản biện khoa học: 25.6.2021

Ngày duyệt bài: 6.7.2021 bên dưới vùng che tuỷ sau 6 tháng, vùng quanh chóp và khoảng dây chằng nha chu bình thường sau 1 năm. Kết luận: Biodentine ${ }^{\mathrm{TM}}$ có thể là một lựa chọn tối ưu cho ứng dụng lâm sàng che tuỷ giản tiếp và có khả năng kích thích tạo ngà sửa chữa.

Tư khoá: Che tuỷ gián tiếp, viêm tuỷ có hồi phục, Biodentine $^{T M}$, xi măng calcium silicate.

\section{SUMMARY}

THE EFFECT OF CALCIUM SILICATE CEMENT (BIODENTINETM) ON REPARATIVE DENTINOGENESIS FOLLOWING INDIRECT DIRECT PULP CAPPING

Objective: Evaluation of the effect of calcium silicate cement (Biodentine ${ }^{\mathrm{TM}}$ ) on reparative dentinogenesis following indirect pulp capping. Methods: A 20-year-old female patient presented the pain in tooth number 37 when eating or cold/hot drinking, occurring several times over the previous one month. Based on the clinical and radiographic examinations, tooth was diagnosed with reversible pulpitis. The tooth was anaesthetized before placement rubber dam for isolation. Decayed tissues were removed using a sterilized high-speed round bur under water coolant. The cavity was disinfected by a sterile cotton pellet soaked in $2,5 \%$ sodium hypochlorite before capping with Biodentine ${ }^{T M}$. The tooth was finally restored with resin composite after one month. Clinical and radiographic evaluation was completed at 6 months and 1 year postoperatively. Results: The patient reported the mild pain occurred for the first post treatment day, but pain was soon alleviated. After 6 months and one year, the patient 